International Journal of Pure and Applied Mathematics

Volume 104 No. 1 2015, 135-143

ISSN: 1311-8080 (printed version); ISSN: 1314-3395 (on-line version)

url: http://www.ijpam.eu

doi: http://dx.doi.org/10.12732/ijpam.v104i1.11

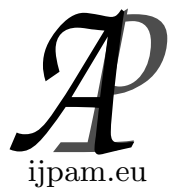

\title{
COMPARATIVE STUDY OF THE DYNAMICS BETWEEN ROLLING BEARINGS OF A DYNAMIC ROTOR
}

\author{
Roberto Outa $^{1}$, Fábio Roberto Chavarette ${ }^{2}$, Glaucia Amorim Faria ${ }^{3}$ \\ ${ }^{1}$ Mechanical Engineering Department \\ UNESP - Univ. Estadual Paulista \\ Brazil Avenue, 56, 15385-000, Ilha Solteira, SP, BRAZIL \\ ${ }^{1}$ FATEC - Faculdade de Tecnologia de Araçatuba, SP \\ ${ }^{2,3}$ Department of Mathematics \\ UNESP - Univ. Estadual Paulista \\ Brazil Avenue, 56, 15385-000, Ilha Solteira, SP, BRAZIL
}

\begin{abstract}
The purpose of this research is to analyze the phenomena connected to a shaft supported by two roller bearings using the concept and theory of Jeffcott rotors, whose dynamic behavior at a given speed, can represent phenomena such as displacement side of the shaft, misalignment of the shaft and to bearing failure, among others. The studies are conducted comparing the accelerations of the theoretical model to the experimental model, whose physical model has a one degree of freedom SDOF.
\end{abstract}

AMS Subject Classification: $70 \mathrm{Kxx}, 34 \mathrm{C} 28,70 \mathrm{~J} 10$

Key Words: dynamics, chaos, vibration, modal analysis, dynamic rotor

\section{Introduction}

Currently the final consumers has required that the products generated by the

Received: July 31, 2015

(C) 2015 Academic Publications, Ltd.

$\S_{\text {Correspondence author }}$ url: www.acadpubl.eu 
companies have better quality and selling price. This fact has caused the manufacturers industries engaged in the improvement of quality control activities, ensuring that the products have reliability, thereby resulting in the improvement of consumer product features. Through this concept the mechanical designs are developed to meet these needs by reducing failures and anticipating the errors found in operative machines. The design of a dynamic rotor is developed by applying different theories and mathematical and physical concepts such as linear and nonlinear dynamical systems, vibration, acoustics, chaos, and others that can be applied in general to review and understanding of your condition.

Dynamic rotors are an area of dynamic that works with mechanical devices, such as rotor, wheel with significant angular movement [1]

Already the ISO defines a rotor as a body suspended by a set of cylindrical bearings or joints allowing to rotate freely around a fixed axis in space. The rotating machines are classified by deformation of the rotation axis, which movement allows the action of a force caused by gyroscope moment caused by the bulk unbalance of a $[2,3]$.

The motivation for the development of these studies is given by the diversity of information and applications of dynamic rotors, and after understanding system behavior and properly characterized, we can deepen the concepts start to control the chaos. Therefore, the aim of this research and analyzing and studying the phenomena connected to the shaft supported by two roller bearings also have the principle to demonstrate the characterization of the experiment on the concept and theory of Jeffcott rotors.

\section{Rotor Dynamics Concept}

The vibration of a rotor dynamic system is characterized by synchronized and unsynchronized vibration depending on the dominant frequency and its excitation source, synchronized vibrations which have a dominant frequency component that corresponds to the axis rotation speed and suffers unbalance by external forces, or by not sync some of the system's elements [4]-[7]. The Figure 1 shows a mass rotation axis $C$, coupled to a disc with the unbalanced center of mass $G$, which is $e_{u}$ unbalance vector which connects $C$ and $G$. The angular velocity of the shaft is $\omega$, and $L$ is length of the shaft.

The equation of lateral displacement in the $x$ and $y$ axes of the system, the response to the excitation at steady state, at Jeffcott system, with mass diferent to zero $[1,2,5]$, and is shown in Figure 1, it can be written as 


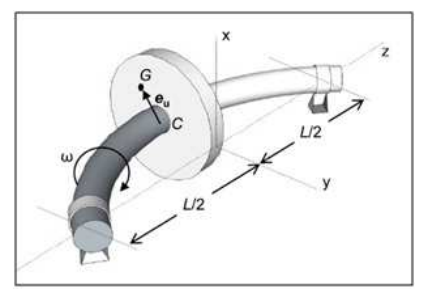

Figure 1: Displacement lateral axis.

$$
\begin{aligned}
& \left(-\omega^{2}+2 i \omega \zeta \omega_{n}+\omega_{n}^{2}\right) U_{x} e^{i \omega t}=e_{u} \omega^{2} \cos (\omega t) \\
& \left(-\omega^{2}+2 i \omega \zeta \omega_{n}+\omega_{n}^{2}\right) U_{y} e^{i \omega t}=e_{u} \omega^{2} \operatorname{sen}(\omega t)
\end{aligned}
$$

The equations 3 and 4 in complex form may be written as,

$$
\left(-\omega^{2}+2 i \omega \zeta \omega_{n}+\omega_{n}^{2}\right) u_{c}=e_{u} \omega^{2}
$$

The theoretical development was described for the condition of a rotor of the lateral displacement of rigid bearings, that is, the alignment of the rotational axis is aligned with the bearing centerline and the moments of inertia acting on the system are not considered.

The gyroscopic effect is introduced into the movement of the dynamic rotor and deduced from a mathematical model. In the gyroscope rotor dynamic effect occurs in misalignment of the shaft with the bearing centerline, whose bearing is considered flexible. The movements which occur in the gyroscopic effect are the results axis rotation around the $x$ and $y$ axis in the center of mass $G$ of the disk, and is represented in figure 2 and considering $y_{G}$ and $x_{G}$ [5].

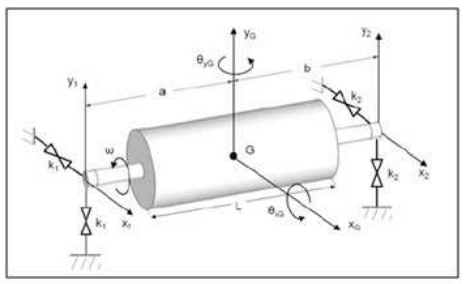

Figure 2: Gyroscopic effect in the center of mass $G$ of the shaft.

The $\theta_{y G}$ and $\theta_{x G}$ are the angles formed by the action of gyroscopic forces in the center of mass disk $G$. The $K_{1,2}$ are the stiffness in relation to the $x$ and 
$y$ axis, and $a$ and $b$ correspond to distance from the center of mass axis $G$ to the end of the shaft, and $L$ is the total distance between shaft bearings. The shaft is influenced by gyroscopic forces of two types, the first being inertia and the second precession. The polar moment of rotational inertia $J_{p}$ of a flexible bearing system and not damped is written as,

$$
J_{p}=\frac{m R^{2}}{2}
$$

The $R$ is the rotor radius. The transverse moment of inertia $J_{t}$ which is the rotational inertia of perpendicular axis on the same axis of rotation and is written as,

$$
J_{t}=\frac{m}{4}\left(R^{2}+\frac{1}{3} L^{2}\right)
$$

Considering that the rotor lateral displacement is $x_{G}$ and is in the $x$ direction, and $y_{G}$ is in the $y$ direction, you can mathematically prove the displacements and rotations from the center of the rotor center of mass $G$ [5]. Therefore, $x_{G}=\frac{1}{L}\left(b x_{1}+a x_{2}\right), y_{G}=\frac{1}{L}\left(b y_{1}+a y_{2}\right), \theta_{x G}=\frac{1}{L}\left(y_{2}-y_{1}\right), \theta_{y G}=\frac{1}{L}\left(x_{2}-x_{1}\right)$. The equations of motion for the translation and rotation of the rotor on the center of mass $G$ are described respectively as,

$$
\begin{aligned}
m \ddot{x}_{G}+\alpha x_{G}-\gamma \theta_{y G} & =0 \\
m \ddot{y}_{G}+\alpha y_{G}-\gamma \theta_{x G} & =0 \\
J_{t} \ddot{\theta}_{x G}+J_{p} \omega \dot{\theta}_{y G}+\gamma x_{G}+\delta \theta_{x G} & =0 \\
J_{t} \ddot{\theta}_{y G}+J_{p} \omega \dot{\theta}_{x G}+\gamma y_{G}+\delta \theta_{y G} & =0
\end{aligned}
$$

The equations 6 and 7 describing the lateral translation movement of the rotor. And the equations 8 and 9 describing the dynamic angular movement. The linearization of the gyroscopic moment in the $x$ and $y$ axes, in the equations 8 and 9 are respectively, $J_{p} \omega \dot{\theta}_{y G}$ and $J_{p} \omega \dot{\theta}_{x G}$. The stiffness parameters of equations 6 to 9 are $\alpha=K_{1}+K_{2} ; \gamma=-K_{1} a+K_{2} b ; \delta=K_{1} a^{2}+K_{2} b^{2}$.

The equations 6 to 9 may also be written vectorially and thus represented by the mathematical model which determines the equation of motion on gyroscopic effect [5],

$$
m \ddot{X}+\omega G \dot{X}+K X=0
$$




\section{Methods and Materials}

\subsection{Mathematical Model}

The mathematical model was developed based on the theory of Jeffcott rotors, whose rotational axis movement at a given speed can show the cause of phenomena such as lateral displacement of the shaft, the shaft misalignment, bearing failures, among others. So the physical model is based on a degree of freedom and the theoretical model results can be displayed in figure 3 considering shaft deflection. The figure 3 shows the deflection axis in the $x y$ plane, considering that the phases are separated angles, that is the angles are decomposed into sine and cosine.

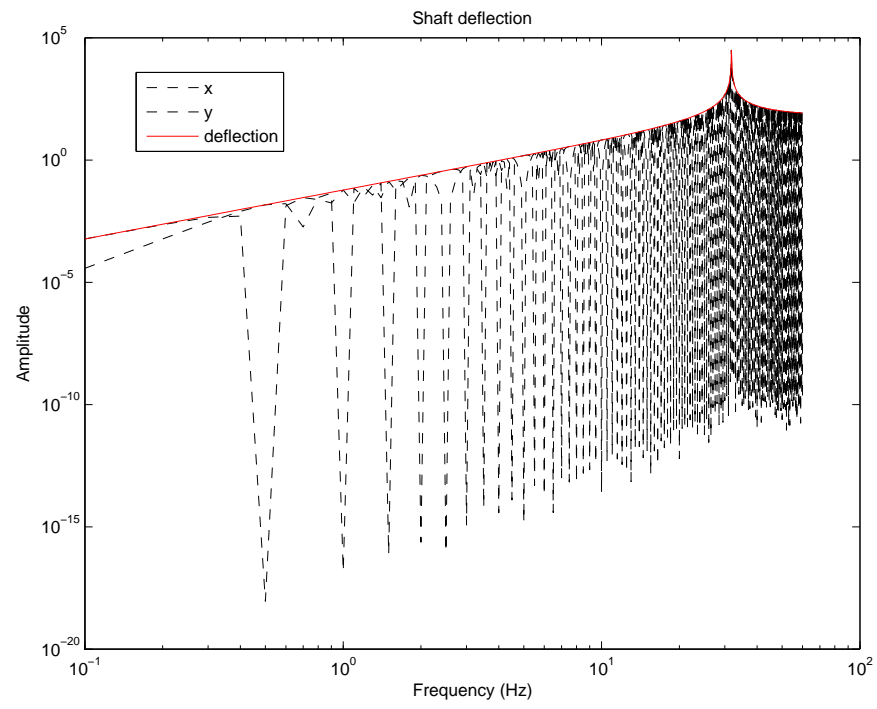

Figure 3: Shaft deflection in the xy plane.

Observe that the black dotted lines represent the deflection of the shaft and are out of phase, and the deflection line continues in red is the result of the equation deflection $=\sqrt{x^{2}+y^{2}}$, corresponding trajectory deflection, the real and imaginary parts.

\subsection{Experimental Model}

The principle all the results obtained applying the experimental model is only of the rotating shaft without increasing a desbalanceadora mass. The experi- 
mental model was assembled with an electric motor with a pulley at the shaft end coupled to this pulley, a set of belt and pulley, connected together. This shaft is supported by two roller bearings. The specifications of the equipment is a $0.5 \mathrm{hp}$ motor, $60 \mathrm{~Hz}$, the frequency inverter is able to operate in frequency $0-60 \mathrm{~Hz}$, the shaft is steel 1045 and it has $12 \mathrm{~mm}$ diameter, wheelbase 128 mm two rolling bearings P205UC205, and one rolling bearing with P205UC205 failures.

The equipment used for measuring the vibration acts in the frequency range of $10 \mathrm{~Hz}$ to $1 K \mathrm{~Hz}$ with approximate sensitivity vibration sensor $15 \mathrm{~mA} \mathrm{DC}$, the requirements of the instruments for measuring the intensity of vibration in rotating machines and alternative satisfy ISO2954 standard. The figure 4a shows the equipment assembly.

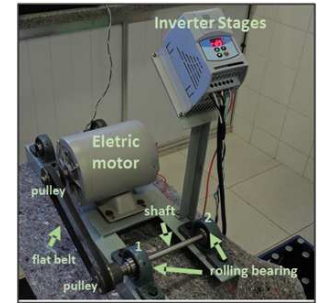

(a) Experiment mounted dynamic rotor .

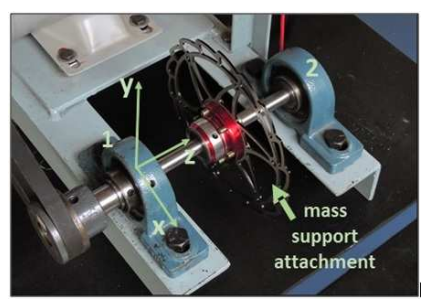

(b) Roller Bearing detail with support for mass fixing.

Figure 4: Model

The figure $4 \mathrm{~b}$ shows details of the holder and the $x, y, z$ which are references for vibration measurements and one disk in the center axis, disposed symmetrically between the two bearings. The measurements of the vibrations were made in two steps, the first step is to assemble two new roller bearings and flawless in points 1 and 2 respectiamente. With arranged and positioned equipment, the $0.5 \mathrm{hp}$ motor is driven, and the phase inverter set to reach the maximum value of $60 \mathrm{~Hz}$, after a while, about 1 minute at the maximum frequency of $60 \mathrm{~Hz}$, it turns off, the result of which are the acceleration data, $\mathrm{m} / \mathrm{s}^{2}$, in route mean square RMS. The The second step, using the same procedure, changes to only one of the bearings, the position 2 , the new bearing which is substituted by one failed, and again the data is collected in acceleration in $\mathrm{m} / \mathrm{s}^{2}$.

The figure 5 shows the results of the theoretical model and the experimental model with new bearings and bearing failed. The figure $5 \mathrm{a}$ and $5 \mathrm{c}$ represent the first phase, in position 1 and 2 respectively with new bearings, while figure $5 \mathrm{~b}$ and $5 \mathrm{~d}$ represent the second phase at the position 1 and 2 , respectively with 
new bearing and bearing failed.
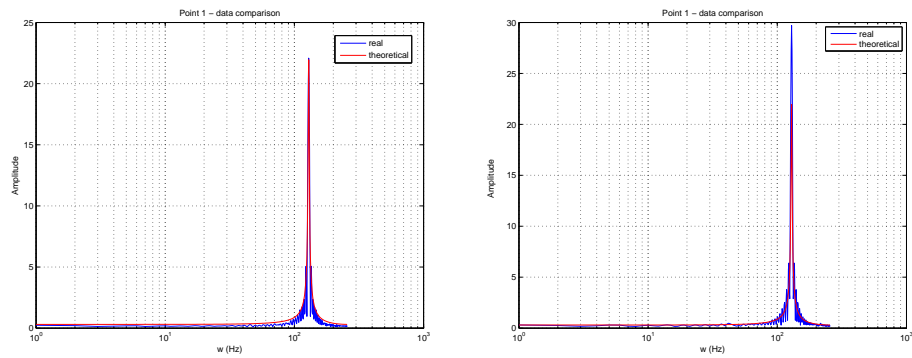

(a)

(b)
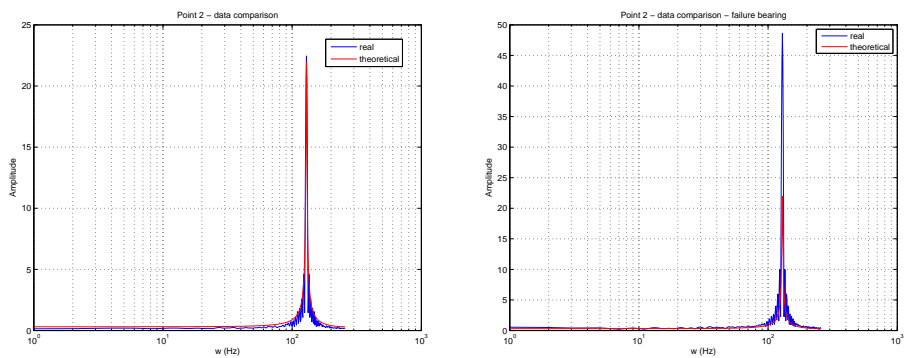

(c)

(d)

Figure 5: Comparison of theoretical and experimental models

\subsection{Discussion of the Results}

It is observed in Figure 5 that the data collected experimentally, in red, in points 1 and 2, only with flawless bearings are very close to the calculated results on the theoretical model, blue, both in amplitude and frequency. Already in points 1 and 2, bearing failed, respectively, the data collected experimentally are far from the calculated results of the theoretical model. These results can be analyzed through the following considerations, shown in Figure 6 .

The error analysis method was applied to the level of confidence $2-95 \%$, and used the equation of finite sample calculation, the result shows that to have $95 \%$ confidence a sample of size 232.305 is required, and the collected sample size 256 , this value is greater than 232.305 and that is that the error is $2 \%$. Table 1 shows the standard deviation and variance in each measured point. 


\begin{tabular}{|c|c|}
\hline $\begin{array}{c}\text { Conditions of } \\
\text { measurement points }\end{array}$ & Analysis \\
\hline $\begin{array}{c}\text { 1 and 2 with bearing } \\
\text { smoothly }\end{array}$ & $\begin{array}{l}\text { Results of data collected from the experimental model are close to the } \\
\text { calculated results of the theoretical model }\end{array}$ \\
\hline $\begin{array}{c}\text { Point 1 and 2 with bearing } \\
\text { smoothly and problems } \\
\text { respectively }\end{array}$ & $\begin{array}{l}\text { Results of data collected from the experimental model are far from the } \\
\text { calculated results of the theoretical model }\end{array}$ \\
\hline $\begin{array}{c}\text { Comparison } \\
\text { measurements of the } \\
\text { points with bearing } \\
\text { smoothly, and points with } \\
\text { bearing smoothly and } \\
\text { problems }\end{array}$ & $\begin{array}{l}\text { The different results show that the used rolling bearing failure behavior in } \\
\text { different phenomena influence the rotating shaft, which cooperates with the } \\
\text { phenomena influence of the lateral displacement of the shaft, the shaft } \\
\text { misalignment, the possibilities of error in assembly, among others. }\end{array}$ \\
\hline
\end{tabular}

Figure 6: Analysis of the results for characterization of the experiment

Table 1: Analysis of the results for characterization of the experiment

\begin{tabular}{cccc}
\hline \multicolumn{4}{c}{ Variance Table and Standard Deviation } \\
Aceleration & Characteristic & Variance & Standart Deviation \\
\hline Theoretical & theoretical model & 0.102741 & 0.320533 \\
point 1 & flawless & 0.151893 & 0.389734 \\
point 2 & flawless & 0.150246 & 0.387616 \\
point 1 & flawless & 0.263224 & 0.513054 \\
point 2 & faulty & 0.369774 & 0.608091 \\
\hline
\end{tabular}

\section{Conclusion}

Through the analysis performed with the positions and their bearings, it is possible to observe that the bearings have good theoretical and experimental results similar or the like, so it is possible to understand the existence of the characterization of the experiment, as well as the certainty of application of the method. While when using a bearing used with failures even the opposite shaft supported in a bearing proper does not eliminate the fault, thereby resulting in that this bearing failure may ultimately influence the phenomena of unbalance, misalignment, bearing failures, among others. Through the experiment characterization it is possible to perform new measurements with the same procedures whose standardization of the methodology helps in case the quality of the acquired data. 


\section{Acknowledgment}

The authors thanks Conselho Nacional de Pesquisas CNPq for financial supports (Proc. $n^{\circ} 301769 / 2012-5$ ).

\section{References}

[1] D.J. Ewins, Modal testing theory, practice and aplication. 2 ed. 16 Couch House Cloister, 10 Hitchin Street, Baldock, Hertfordshire, England, SG7 $6 \mathrm{AE},(2000), 562$.

[2] G. Genta, Dynamics of rotating systems, Springer Science+Business Media,Inc., 233 Spring Street, New York, NY 10013,USA, (2005), 674.

[3] Y. Ishida, T. Yamamoto, Linear and Nonlinear Rotordynamics, WileyVCH Verlag and Co. KGaA, Boschstr. 12, 69469 Weinheim, Germany, (2012), 454 .

[4] L.H.A. Monteiro, Sistemas dinmicos, 3 ed., editora Livraria da Fisica, (2011).

[5] S.Y. Et Al. Yoon, , Z. Lin, P.E. Allaire, Control of surge in centrifugal compressors by active magnetic bearings, theory and implementation, Springer London Heidelberg New York Dordrecht, Springer-Verlag London (2013), 292.

[6] L. Meirovitch, Principles and techniques of vibrations, Prentice Hall, Inc., Upper Saddle River, New Jersey 07458, (1997), 694.

[7] M. J. Crocker, Handbook of noise and vibration control. Hoboken: John Wiley and Sons, (2007), 1569. 
